\title{
SIMILITUDES DE LOS PROCESOS MIGRATORIOS AMERICANOS A TRAVÉS DE LA HISTORIA ORAL: EL CASO DE ANDALUCÍA ORIENTAL
}

\author{
María Dolores Pérez Murillo. \\ Universidad de Cádiz

\section{RESUMEN:}

El presente artículo está en la línea de investigación referida a "movimientos migratorios hacia y desde América Latina" que, desde 1992, coordino en la Universidad de Cádiz (España). A través de esta investigación pretendo realizar un análisis comparativo acerca de las similares características que posee en sí todo fenómeno migratorio, y para ello hemos elegido como campo de trabajo la subregión de Andalucía Oriental, la Andalucía del Mediterráneo, que a finales del siglo XIX y hasta mediados de la pasada centuria fue lugar de diáspora migratoria hacia América Latina; pero al comenzar el siglo XXI ese mismo escenario se ha convertido en espacio receptor de inmigrantes, y entre ellos los latinoamericanos. Las causas y características de sendas diásporas son similares. XX.

Palabras Clave; Movimientos Migratorios, América Latina, Andalucía, siglos XIX y

\begin{abstract}
:
The present article is in the line of investigation(research) recounted to " migratory movements towards and from Latin America " that, from 1992, I coordinate in the University of Cadiz (Spain). Across this investigation(research) I try to realize a comparative analysis it(he,she) brings over of the similar characteristics that it(he,she) possesses in yes any migratory phenomenon, and for it we have chosen as work camp the subregion of Oriental Andalusia, the Andalusia of the Mediterranean, that at the end of the 19th century and until middle of last century it was a place of migratory diaspora towards Latin America; but on having begun the 21 st century the same scene(stage) has turned into space immigrants' recipient, and between(among) them the Latin Americans. The reasons and characteristics of paths diasporas are similar.
\end{abstract}

Key Words: Migratory movements; Latin America, Andalusia, $19^{\text {th }}$ and $20^{\text {th }}$ century. 


\section{1.- INTRODUCCIÓN}

El presente artículo pretende reflexionar acerca de las similitudes que existen en todo proceso migratorio, al tiempo que nos recuerda que la Andalucía mediterránea, hoy receptora de inmigrantes, contó en su haber con toda una tradición de diáspora que, desde finales del siglo XIX, se materializó en el éxodo al norte de África (Orán) ${ }^{1}$ y hacia América Latina (Cono Sur, prioritariamente) sobre todo en la primera mitad del siglo $\mathrm{XX}^{2}$. A mediados de la década del cincuenta y durante la del sesenta, toda la región andaluza se convirtió en la cantera que nutrió de mano de obra a la Europa desarrollada ${ }^{3}$ a otras regiones españolas.

En repetidas ocasiones he tenido la oportunidad de dar alguna que otra charla sobre migraciones en distintos niveles de la docencia, tanto secundaria como universitaria, y al preguntar a los alumnos si en sus familias había habido algún emigrante, casi todos recordaban a los abuelos, padres, tíos o parientes emigrados en Europa o en Cataluña, pero ignoraban totalmente que, hace poco más de 50 años, los andaluces habían emigrado a América Latina y al norte de África. Esa "desmemoria" se hace cada vez mayor, e incluso es potenciada mediaticamente, así dentro de una ó dos décadas, los jóvenes peninsulares, de raza blanca, harán alarde de una "amnesia", propia de nuevos ricos, que ignorará como unos compatriotas del siglo pasado padecieron el exilio, la emigración y el desgarro de abandonar sus lugares de origen. Por ello, para evitar la atrevida ignorancia y el olvido, estamos los historiadores, centinelas del tiempo y del espacio, recordando, en el más puro sentido etimológico ${ }^{4}$, que no siempre fuimos "los porteros de primer mundo", encargados de detener a la "avalancha de inmigrantes", y que también a nuestros antepasados se les negó la tan "cacareada" ciudadanía por "carecer de papeles", también fuimos "clandestinos"5

Por ello para no olvidar nuestra condición de emigrantes es conveniente refrescar la memoria, y que nos hablen las historias de vida de la gente sin historia, de las mujeres y hombres anónimos, de los que no aspiran a perpetuarse en archivos ni en "panteones" de hombres ilustres, que ellos, rescatados de nuestra "amnesia", muchas veces generada por aburridas series numéricas, propias de libros de texto, "políticamente correctos", nos refieran su éxodo a tierras americanas, que, por ironía del destino, es similar al de los latinoamericanos que, en la actualidad, habitan tierras, otrora, de diáspora.

El Área de Historia de América de la Universidad de Cádiz (concretamente el Grupo de Investigación "Intrahistoria, Oralidad y Cultura en América Latina y Andalucía) lleva desde 1992 investigando la Historia Oral de la emigración andaluza hacia América Latina ${ }^{6}$, y desde hace siete años trabajando con los testimonios orales de latinoamericanos en Andalucía ${ }^{7}$. Hasta ahora las fuentes orales que podemos ofrecer se refieren: por un lado a la diáspora migratoria de la Andalucía del Mediterráneo a Brasil y a la Argentina desde finales del siglo XIX hasta los

\footnotetext{
${ }^{1}$ VILAR , Juan Bautista : “Inmigración y presencia españolas en el norte de África (siglos XIX y XX)”. (págs. 10-21). España, país de migraciones. Revista Migrance 21. Editions Mémoire-Génériques. Tercer Trimestre. 2002.

2 PÉREZ MURILLO, María Dolores, coordinadora : Oralidad e Historias de Vida de la Emigración andaluza hacia América Latina (Brasil y Argentina) en el siglo XX. Servicio de Publicaciones de la Universidad de Cádiz. Cádiz, 2000

${ }^{3}$ MARTÍN DÍAZ, Emma y RUIZ MORALES, Fernando C.: " Andaluces en Europa: De la supervivencia a la inserción social" (págs. 44-57). España, país de migraciones, op., cit.

${ }^{4}$ GALEANO, Eduardo : El libro de los abrazos 1 a edición diciembre de 1989. Catálogos Editora. Buenos Airea 1996 (sexta reimpresión argentina). Recordar proviene del "cords-cordis" que significa "corazón"; por tanto "re-cordar" es "volver a pasar por el corazón"

${ }_{5}^{5}$ Traemos a colación el estribillo de aquella canción (1998) de Manu Chao : "Solo voy con mi pena/ sola va mi condena/ correr es mi destino para burlar la ley/ perdido en el corazón/ de la grande babilón/ me dicen el clandestino/por no llevar papel.

${ }^{6}$ PÉREZ MURILLO, María Dolores, op. , cit.

${ }^{7}$ DÍAZ BUZÓN, Eva María : Los indígenas saraguros (República de Ecuador) y su emigración a Vera (Almería) a través de la Historia Oral. Tesis Doctoral, dirigida por María Dolores Pérez Murillo, y defendida en la Universidad de Cádiz el 12 de septiembre de 2003, publicada en formato electrónico (Tesis Doctorales de la UCA).
} 
años sesenta del siglo XX; y por otro, a las historias de vida de inmigrantes indígenas ecuatorianos, de la etnia saragura, residentes "con y sin papeles" en la ciudad mediterránea de Vera (Almería) ${ }^{8}$. Hay que especificar que el interés por este colectivo de inmigrantes ecuatorianos se remonta al año 1997, fecha en la que tuvimos la oportunidad de contactar con la comunidad de indígenas saraguros (Loja-Ecuador) a través del Programa Intercampus (Europa/América Latina) de la AECI (Agencia Española de Cooperación Internacional) entre las Universidades de Cádiz (España) y la Nacional de Cuenca (Ecuador). A partir de ese momento nuestras investigaciones de Historia Oral de las Migraciones adquirieron un sentido más universal, pues no sólo investigábamos la diáspora mediterránea sino la presencia de inmigrantes latinoamericanos en la Andalucía Oriental, bañada por el Mediterráneo.

Lamentamos que los libros de texto, editados en la Comunidad Autónoma Andaluza, obvien o traten superficialmente los temas de emigración. Ello pone en evidencia la negativa a asumir la propia historia andaluza, que va más allá de himnos, banderas, apologías, y fronteras. Admitir que hemos sido tierra de diáspora emigratoria evitaría la xenofobia y el aparheidt que condena a miles de inmigrantes a ser ignorados o a vivir infrahumanamente por falta de una adecuada inversión estatal en infraestructuras de acogida, máxime estando Europa falta de inmigrantes que trabajen, llenen nuestras aulas escolares y coticen a la seguridad social para poder mantener la incipiente sociedad del bienestar, que en España se inició en los años ochenta del pasado siglo XX. Al respecto hacemos alusión a un artículo de prensa ${ }^{9}$ de mayo de 2004 en el que se alertaba acerca de la necesidad que Europa tiene de inmigrantes, en él se especificaba que durante los veinte próximos años habría que acoger a 650.000 inmigrantes anuales, de los cuales 250.000 serían suministrados por los nuevos países que, en los últimos años, se han incorporado a la Unión Europea; y los 400.000 restantes deberían provenir de otros Continentes (África, Asia y América Latina). Por todo ello, resulta absurdo que el gobierno de José $\mathrm{M}^{\mathrm{a}}$ Aznar invirtiera un millón de euros en la frustrada "Operación Ulises", que en la primavera de 2003 se dedicó a perseguir "pateras" en el Mediterráneo Occidental ${ }^{10}$; o que el gobierno de Rodríguez Zapatero se dedique a "repatriar" cayucos o mantenga la vergonzosa verja de Ceuta, dando lugar a los luctuosos acontecimientos de otoño de 2005. Igualmente, consideramos también improcedente el mensaje, casi "apocalíptico", de los medios de comunicación que continuamente bombardean a los ciudadanos con términos como el de "avalancha de inmigrantes".

\section{2.- LA ANDALUCÍA DEL MEDITERRÁNEO COMO ESCENARIO DE DIÁSPORA Y ACOGIDA MIGRATORIA HACIA Y DESDE AMÉRICA LATINA.}

En cuanto a la extracción socio-profesional de los andaluces que emigraron a América, a finales del siglo XIX y a comienzos del XX, originarios del área mediterránea (provincias de Málaga, Granada y Almería), hemos de aclarar que no eran los más pobres, no eran jornaleros, sino una clase integrada por pequeños comerciantes, obreros de ingenios azucareros, muchos de ellos cualificados, algunos funcionarios, adolescentes desertores de la Guerra de África y, sobre todo, pequeños propietarios rurales (minifundistas) que, ante la ineficacia del Estado frente a la crisis de la plaga de filoxera y de la caña de azúcar, se vieron obligados a vender el minifundio, el pequeño negocio, o casa de su propiedad para pagar a las mafias de la emigración que ofrecían en los puertos de Málaga, Algeciras y Cádiz el viaje a la "ubérrima" América que, por aquellos momentos, finales del siglo XIX y comienzos del XX eran Brasil y Argentina con sus políticas de "puertas abiertas". Así pues, entre 1880, inicios de la crisis de la plaga de la filoxera, y 1935, vísperas de la Guerra Civil, por los puertos andaluces embarcaron rumbo a América casi

\footnotetext{
${ }^{8}$ La Tesis de Eva María Díaz Buzón, mencionada más arriba, fue elaborada a partir de testimonios del trabajo de campo conjunto que la referida doctora y yo realizamos en Vera (Almería) en julio de 2002.

9 Artículo de "El País", sábado 29 de mayo de 2004.

${ }^{10}$ Artículo o nota de prensa de "El País", sábado 29 de mayo de 2004.
} 
un millón de personas ${ }^{11}$, según cifras oficiales. A mediados del siglo XX (años cincuenta) la Andalucía Mediterránea experimenta una segunda gran oleada migratoria, de pequeños propietarios de algo (una casa o minifundio) que les posibilitara pagarse el viaje a América, y de este modo, siguiendo las redes familiares y de paisanaje, establecidas en Brasil y, sobre todo, en la Argentina, huirán de la pobreza material y espiritual del franquismo, buscando en América nuevas oportunidades; hoy los hijos, nietos, e, incluso, biznietos de aquellos primeros emigrantes de comienzos del siglo XX, buscan la acogida en la Europa de sus ancestros ante la crisis del capitalismo salvaje que actualmente ahoga a América Latina.

Los inmigrantes ecuatorianos, indígenas saraguros, de los que poseemos testimonios recabados en la mediterránea ciudad de Vera, son de similares características a los andaluces del Mediterráneo que emigraron hace un siglo a América, pues nos hallamos ante un colectivo formado por pequeños propietarios rurales, muchos de ellos con estudios universitarios medios, que ante la crisis finisecular del Continente Latinoamericano y, en el caso que nos ocupa, de la República del Ecuador, se han visto forzados a abandonar su lugar de origen y emprender el incierto desgarro del éxodo a unas tierras lejanas, del Mediterráneo, semidesérticas, convertidas en "ubérrimas" por el "arte de magia" de la agricultura de invernadero, auténtico atentado al equilibrio ecológico y a la salud humana ${ }^{12}$. Los inmigrantes que trabajan en los invernaderos, muchos de ellos latinoamericanos, presentan unas pésimas condiciones de vida y de trabajo, y debido a la ausencia de una política pública de acogida se están generando cada vez más bolsas de miseria humana y de exclusión social, que vienen provocando fuertes actitudes xenófobas, principalmente contra el colectivo marroquí, de similar cualificación profesional que los latinoamericanos. Traemos a colación lo siguiente:

"La necesidad de mano de obra ha hecho que los empresarios contraten a inmigrantes, en muchos casos sin documentación, lo que les ha permitido el ahorro de pago a la Seguridad Social, y pagar salarios miserables, aprovechándose de la imposibilidad de los inmigrantes de plantear reclamaciones, dada su situación irregular. Pero aunque los inmigrantes irregulares eran bien recibidos como mano de obra en los invernaderos, eran rechazados y marginados en el resto de los ámbitos sociales, comercios, viviendas, etc. Así el número de inmigrantes

\footnotetext{
${ }^{11}$ MATEO DE AVILÉS, Elías : Emigración andaluza a América 1880-1955. Málaga, 1996

${ }^{12}$ La agricultura bajo plástico o de invernadero se introdujo en la costa del Poniente y del Este almerienses y en la zona oriental de la costa granadina a mediados de los años sesenta del siglo XX. En el caso concreto de la costa granadina la mayoría de estas parcelas de invernaderos tienen su origen en los planes de colonización del franquismo que posibilitaron a la población más desfavorecida, a los jornaleros, a los que jamás pudieron soñar con emigrar a América por carecer de bien material alguno, una casa y una parcela (de invernadero) que en menos de una década proporcionó a esta zona desértica de parte de la costa granadina (Carchuna, Calahonda, Castell de Ferro, La Rábita, La Mamola, Albuñol) una prosperidad insólita. Los parcelistas originarios, beneficiados por el franquismo, y muchos emigrantes retornados de Europa fueron comprando más tierras y roturando cada vez más el "desierto" costero hasta convertirlo en un "mar de plástico", Meca del materialismo, y atentado al medio ambiente por lo artificial de las hortalizas y frutos que dichos invernaderos producen y sobre todo por la constante emisión a la atmósfera de $\mathrm{CO} 2$, provocada por los "plásticos". Además la abundancia de estos invernaderos está provocando una mayor desertización de la tierra y un aumento insólito de las temperaturas de la zona. Los invernaderos, como un cáncer, avanzan sobre la caña de azúcar de las vegas costeras granadinas (Motril y Salobreña). La alta rentabilidad de la agricultura "bajo plástico", el individualismo y la falta de voluntad política para ayudar a los agricultores (minifundistas) a mantener los cultivos tradicionales están ocasionando un grave atentado ecológico y humano en el Mediterráneo andaluz (Almería y Granada), y digo humano porque muchos inmigrantes, venidos de África y América Latina, el único trabajo que encuentran en Andalucía es el de los invernaderos donde trabajan en pésimas condiciones : manipulando insecticidas sin mascarillas y a temperaturas superiores a $40^{\circ} \mathrm{C}$., trabajos que jamás realizarían los españoles por el exiguo salario de 3 euros por hora de trabajo; a lo que hay que añadir las pésimas condiciones de vida de dichos inmigrantes que viven sin agua y sin luz en cortijos derruidos, en peores condiciones que los animales del campo. Además de todo lo expuesto, son víctimas de la xenofobia de la población autóctona, al respecto no podemos olvidar los acontecimientos del pueblo de El Ejido (Almería) en el año 2000, pueblo cuyo alcalde es el más votado de toda España, y es lamentable que pronuncie frases como ésta : "! Qué pocas gente hay en este pueblo por la mañana y cuanta gente hay por la tarde!", dicha frase nos evidencia la necesidad de mano de obra inmigrante para los invernaderos; pero luego, por la tarde , cuando toca "compartir" los espacios de ocio y recreo nos molesta que allí estén los inmigrantes. Lo más lamentable de todo es que muchos andaluces, nuevos ricos del "plástico", han olvidado que alguna vez fueron pobres y emigrantes también. (Esta nota a pie de página es un comentario personal propio, basado en mi conocimiento de la zona por ser originaria de Motril (Granada) ).
} 
continuaba aumentando al mismo tiempo que su marginación, y pronto comenzaron los vecinos a quejarse de la inseguridad que esta bolsa de pobreza causaba. No todos los inmigrantes se encuentran en la misma situación, algunos llevan viviendo en la comarca desde finales de los años 80, cuentan con permiso de trabajo y residencia, pagan impuestos, son propietarios de comercios y viviendas y han reagrupado a sus familias o las han formado aquí. Sin embargo, la mayoría de los inmigrantes malviven en cortijos abandonados, y chozas de plástico, hacinados en grandes grupos, irregulares la mayor parte de ellos, y en algunos casos menores de edad, formando un verdadero aparheid"13

Como el objetivo primordial del presente artículo es buscar las similitudes de la emigración hacia y desde América Latina en el escenario del Mediterráneo andaluz, hemos seleccionado una serie de testimonios orales sobre las causas e infraestructura material del proceso migratorio, el desgarro humano, y el arquetipo de emigrante:

- Las causas de la diáspora son en ambos casos, casi siempre, las crisis económicas y la ausencia de unas correctas políticas públicas que eviten el éxodo.

- La infraestructura material o las fuentes de financiación de estos viajes transatlánticos o transcontinentales son en sendos casos las mismas, ya que el que emigra debe poseer algún bien material, casa o tierra, que vender o hipotecar para poderse pagar el viaje y todos los gastos subsidiarios, y para ello tiene que buscar a algún usurero, denominado chulquero en Ecuador, para que proporcione la transacción del capital inmueble a dinero líquido. El siguiente paso es contactar con las mafias de la emigración (denominados: ganchos en la Andalucía y coyotes en muchos países americanos, y concretamente Ecuador), mafias que proporcionan, previo pago, el viaje y falsos documentos o dinero para entrar en el país receptor.

- Igualmente queremos dejar bien claro que nadie emigra por gusto. Toda emigración es un profundo desgarro.

- El prototipo socio-económico de emigrante, que emprende la aventura transatlántica desde y hacia el Mediterráneo andaluz, aunque lo hace por causas de tipo económico, no siempre pertenece al colectivo más pobre, pues debe disponer de un mínimo numerario que, como hemos señalado más arriba, le permita financiar su viaje. Los sectores más deprimidos económicamente, los verdaderamente pobres, los que nada poseen difícilmente podrán emprender la "aventura" migratoria.

Sin más preámbulos, pasemos a que sean los verdaderos protagonistas de la emigración los que nos refieran las causas y características de su éxodo. Para ello hemos seleccionado una serie de testimonios de andaluces y de ecuatorianos (indígenas saraguros) que, gracias a la Historia Oral en la que llevamos investigando más de una década, nos reconstruyen las realidades de los movimientos migratorios desde un punto de vista cualitativo e intrahistórico:

\footnotetext{
${ }^{13}$ Informe de los sucesos xenófobos en El Ejido. "Datos Generales sobre El Ejido". Webjornal zum. Flüchtlingskongress vom 21.April bis 1. Mai in Jena

http:// www.humanrights.de/doc_en/archiv/congress/2000/04/24/11.html
} 


\section{3.- CARACTERÍSTICAS DE LA EMIGRACIÓN DE LOS ANDALUCES DEL MEDITERRÁNEO A AMÉRICA LATINA A TRAVÉS DE EXTRACTOS TESTIMONIALES}

\subsection{Causas de la emigración.}

-Una causa de la primera gran oleada emigratoria hacia América Latina fue la crisis de la filoxera de finales del siglo XIX y el endeudamiento del minifundista rural que no pudo hacer frente a los cobradores del fisco y a los usureros locales. Por estas fechas en las actuales provincias de Málaga y Granada el Banco de España se quedó con 800.000 minifundios, cuyos propietarios, desatendidos por el Estado, no tuvieron más vía que la de "cruzar el charco":

"En los carnavales de un pueblo malagueño en 1889 iban estas máscaras : Uno hacía de recaudador de contribuciones y consumos, llevaba, a cierta distancia los peroles y objetos embargados y en las espaldas llevaba este letrero : "es peor que la fiebre amarilla". Iba persiguiendo a cuatro máscaras, disfrazadas de contribuyentes arruinados. Todos huían llevando escrito este letrero: Vámonos para Buenos Aires que detrás viene el cólera" "14

-Los males del minifundio en las tierras costeras de la Andalucía del Mediterráneo a comienzos del siglo XX fue una de las causas de diáspora de familias nucleares a Brasil y al Río de la Plata. Actualmente estas mismas tierras "pobres y secas" se transformaron en prósperos invernaderos que emplean a mano de obra inmigrante, de origen marroquí y latinoamericano. El siguiente testimonio fue tomado en la primavera de 1992 a una mujer de 67 años en Carchuna (Costa de Granada), propietaria de invernadero gracias a los planes de colonización del franquismo, cuyos abuelos habían emigrado a Brasil a causa de la dureza del lugar de origen:

"Tierras pobres, secas, con viñedos, higueras, almendros, que cuando llovía fuerte las aguas arramblaban con todo. Alli se daba el trigo, la cebada, los guisantes, los garbanzos; pero estos campos daban poco dinero por la escasez de terreno. No habia luz, ni agua, ni carreteras. Los niños trabajaban desde su más tierna infancia en trabajos como espantar gorriones con latas, cuidar de las cabras, etc., y las niñas en cuidar de sus hermanos más pequeños... Campos sacrificados en donde crecian las malas hierbas, y después de tanto trabajar si las lluvias no llegaban a tiempo no se recogía nada." 15

Otro testimonio, tomado en 1994 en Jerez de la Frontera a una mujer de 70 años, nos corrobora también de los perjuicios del minifundio en la sierra de Cádiz, concretamente en Villaluenga del Rosario :

“Mi familia paterna tenía unas, unas tierrecitas ¿no?, mi abuela tenía unas tierrecitas heredadas de mi abuelo y claro..., ellos eran..., eran ocho hijos lo que tenían, y mi abuela se quedó viuda muy joven. Mi padre tenía 16 años, que era el segundo de los ocho hijos, y el más chico tenía 8 meses, y claro, pues los más chicos irían ayudando a lo poquito que tenían, y los mayores dirían: "pues a ver si nosotros podemos por otro sitio ayudar... Mi padre emigró a La Habana, donde yo nací porque en el pueblo (Villaluenga del Rosario, provincia de Cádiz) no habia futuro..." "I6

- Reflejamos en el siguiente texto la crisis del azúcar en las costas de Málaga y Granada y el enfrentamiento de los cultivadores de la caña ante el bajo precio impuesto a su producto por los ingenios azucareros (fábricas de azúcar) como únicas vías de transformación y comercialización de la caña de azúcar. La mayoría de los ingenios existentes en la costa del Mediterráneo, de Málaga hasta Adra, eran propiedad de nobles españoles, como el famoso

\footnotetext{
${ }^{14}$ MATEO DE AVILÉS, Elías, o.c.

${ }^{15}$ PÉREZ MURILLO, María Dolores : "Estudio cualitativo y testimonios de la emigración del sur de España a América Latina en el siglo XX". Artículo publicado en el monográfico sobre "Migraciones" de la Revista RÁBIDA. Ecxma. Diputación Provincial de Huelva. Huelva, enero 2003.

${ }^{16}$ Ibídem
} 
marqués de Larios. Al respecto, un inmigrante de la Costa de Granada, residente en Rosario (República Argentina) en julio de 1993 nos narró lo que sigue:

"Estos motrileños de comienzos de siglo tuvieron que partir de su lugar de origen para venir a la Argentina y a Brasil por diversas causas; pero una de ellas, la principal, fue la quema de la fábrica del marqués de Larios en Motril, en 1902 ó 1903. Todo el pueblo estaba comprometido, llegaron a tener tal compromiso, que el pueblo llegó a la casa cuatel de la guardia civil y los obligaron a salir, había unos 15 guardias civiles que, vestidos de uniforme y con armas largas, encabezaban la manifestación, y el pueblo iba detrás apuntándoles para que estos señores no hicieran uso de sus atributos. El alcalde de Motril, por aquel entonces, don Luis Vinuesa, iba al frente de la manifestación coaccionado por el pueblo (aunque logró escapar de la manifestación y, disfrazado de mujer, huyó de Motril). Los manifestantes llegaron al ingenio del marqués de Larios y lo quemaron (no estallando la ciudad de milagro, pues cerca de la quema había grandes depósitos de alcohol). El señor Larios, absentista y residente en Málaga, ciudad donde una calle céntrica lleva su nombre, cuando se enteró de la quema de su ingenio, y estando en el casino malagueño, sacó, con gran arrogancia, de una pitillera de oro un cigarrillo, lo encendió y dijo : "ya lo sentirán los motrileños..., lo mismo que este pitillo me importa a mí la fábrica de Motril”, y, acto seguido, comenzó una terrible represión que obligó a estos pequeños cultivadores y obreros del azúcar a salvar su vida, poniendo mar de por medio, y por la vía ilegal de Gibraltar emigraron a Tucumán, zona azucarera, por antonomasia, de la República Argentina"17

- El siguiente testimonio es el de una mujer que, cuando partió para la Argentina en 1952, contaba con 26 años de edad y estado civil soltera, en su lugar de origen tenía un buen status social, ya que su familia y ella eran propietarios de una tienda de comestibles (ramo de ultramarinos), ubicada en una céntrica calle de la ciudad de Motril (Granada). Su hermano con 30 años, soltero también, era persona inquieta, con la necesidad de ver mundo, de salir de la asfixiante sociedad de la posguerra, además simpatizaba con las ideas anarquistas, y géneros de su tienda eran vendidos a "enlaces" del maqui que actuaba en las cordilleras costeras granadinas. La situación llegó a ser tan comprometida, que antes de llegar a más, decidieron vender todo el patrimonio, y enrolarse en la aventura americana los cuatro miembros de la familia : el padre, de 60 años; la madre, de 58; la hermana de 26; y él de 30 años. En el testimonio se elude la causa real de esa emigración, todo parece capricho de un "treintañero" aventurero y una pasiva familia detrás de él. Este testimonio fue tomado en Rosario (República Argentina) a una mujer de 68 años en julio de 1993 :

"Nos vinimos a América, porque mi hermano quería venir a América, y quería venir a América, y nosotros empezamos a decir: iAy, si se va el niño lo vamos a perder, si se va lo perdemos! Y estábamos una noche sentados en la mesa de camilla, en el gabinete, y se...dijo papá: ¿y si nos fuéramos todos?. Bueno, y ahí..., nos vamos y nos vamos"18

\subsection{Infraestructura material o fuentes de financiación del viaje desde el Mediterráneo hacia América Latina.}

En los tres siguientes testimonios, tomados en la Argentina, no existe miedo ni reparo alguno para hablar de las "mafias" de la emigración, de los ganchos, sobre todo del siniestro "don Francisco", apodado también "el tío de Cádiz". Dicho personaje recorría los pueblos andaluces prometiendo "Eldorado", cobraba anticipadamente el pasaje del barco y todos los trámites burocráticos al precio de 10.000 pesetas (60 euros, que en el año 1952 eran como 6.000 euros actuales) por una familia de cinco miembros (matrimonio y tres hijos pequeños, de 7, 5 y 1 años) que deberían viajar en la panza de un barco mercante en condiciones infrahumanas. Lo normal es que don Francisco, habiendo cobrado por adelantado, se olvidara de sus "protegidos",

\footnotetext{
${ }^{17}$ Ibídem

${ }^{18}$ Ibídem
} 
estos se veían obligados a emprender el primer tramo de su viaje, a saber: llegar a Cádiz y esperar unos meses hasta que hubiera plazas disponibles en los mercantes, durante ese tiempo los "presuntos" emigrantes se alojaban en el hostal (pensión) que el "gancho" tenía en una céntrica calle del casco antiguo de Cádiz., alguno (como muestra el tercer fragmento) se arruinó esperando el barco de las Américas, y, avergonzado de volver al lugar de origen, decidió quedarse en la "puerta del Nuevo Mundo", en Cádiz, en condiciones de semimendicidad:

"Entonces paseaba por las calles de los pueblos andaluces un tristemente célebre personaje que fue don Francisco, pasaba por las calles de Motril, y claro, lo adoraban como a un apóstol, porque aquel hombre vendía pasajes para América. Era un sevillano, residente en Cádiz, al que popularmente llamaban "el tío de Cádiz", éste era un testaferro de otros, que estaban a su vez conectados con los cónsules americanos y con las autoridades argentinas, y en contubernio indecoroso por ambas partes se fructuaban las famosas cartas de llamada donde aparecía un reclamante en Argentina que no existía, y un señor que pagaba por esta carta de llamada. Así se legalizaba lo que era ilegal. Era un comercio de trata de blancos.” 1996). ${ }^{19}$

(Testimonio de un inmigrante de 78 años, residente en Rosario (Argentina), agosto de

“ Mi marido habló con él y don Francisco le dijo que "sí que era verdad que podía venderle los pasajes para irse a América; pero que tenía que darle la plata adelantada". Entonces nosotros agarramos y juntamos la plata que habíamos juntado después de vender dos pedacitos de tierra, y se la metimos en el bolsillo al hombre éste (a don Francisco), sin que él la contara ni nada. Le dimos 10.000 pesetas a cuenta, él se fue a Cádiz y quedó en llamarnos; pero pasaron los meses y no nos llamó, y entonces nos presentamos en Cádiz, y allí ,mientras esperábamos el barco, estuvimos alojados en la pensión de don Francisco durante tres meses, habiéndole de pagar 5.000 pesetas más.”

(Testimonio de una inmigrante de 78 años residente en San Miguel de Tucumán (Argentina), julio de 1993.). ${ }^{20}$

"Cuando estábamos en Cádiz, esperando embarcar vimos a uno que tenía una confitería enfrente de nosotros, en la calle "catalanes"; y cuando lo vimos en Cádiz, ya había (transcurrido) un mes o más... que se había ido de Motril para embarcar para América, y lo encontramos con un carro tirando de él, llevando bultos, que sé yo, porque no sabía qué hacer, porque ya no tenía nada, y no tenía dinero, estaba en la calle...” (Argentina) $^{21}$

(Testimonio, tomado en julio de 1993, a un inmigrante residente en Rosario

Otro testimonio nos detalla como los trámites para emigrar a la Argentina de los años cincuenta eran complicados burocráticamente y caros, necesitándose varios documentos, entre ellos: carta de llamada que, normalmente, la expedían los consulados hispanoamericanos ubicados en Cádiz o en otros puertos de Andalucía, la carta o contrato de trabajo era un documento irreal, falso, porque nadie reclamaba allá, pero al entrar en Santos, Montevideo o Buenos Aires había que presentarla. En el testimonio, que presentamos a continuación, el protagonista recurre a las redes de paisanaje, a los familiares que tiene en Buenos Aires, para que le manden la "carta de llamada" o contrato de trabajo, y así evitar pagar ese documento al consulado argentino:

"Para irme tuve que conseguir una carta de llamada, pues con Franco no se podía salir de aquí, a pesar de que yo estuve en la guerra con Franco, porque me pilló con Franco; pero si me hubieran tocado los rojos, lo mismo hubiera estado con ellos. No dejaban salir a nadie de España- puntualiza la esposa-. Entonces para conseguir la carta de llamada escribí a una prima mía, casada con un militar residente en Buenos Aires, que amparándose no sé en qué cosa, me envió una carta reclamo diciendo que yo iba a trabajar allí, que no iba a buscar trabajo, sino

\footnotetext{
${ }^{19}$ Ibídem

${ }^{20}$ Ibídem

${ }^{21}$ Ibídem
} 
que ya tenía trabajo allí, en Argentina. La madre de mi prima era hermana de mi madre, esta tía materna se había marchado a la Argentina mucho antes de que yo naciera".

(Testimonio tomado a un matrimonio de retornados, de más de 70 años, en Motril (Granada), junio de 1993). ${ }^{22}$

- Los dos siguientes testimonios, procedentes de la misma persona, nos muestran con todo detalle las dificultades que el emigrante de los años cincuenta tiene para salir de España y como ha de autofinanciarse su viaje contactando previamente con las mafias portuarias, señalando con todo detalle (en el segundo extracto) el precio exacto del viaje

"Como era dificultoso conseguir un pasaporte en la España de aquella época surgió una picaresca en la falsificación del mismo, y mucha gente tuvo que pagar un sobreprecio para marchar. Tras venderlo todo, muchos se quedaron en tierra en Cádiz. En esta ciudad, lugar del embarque, había una mafia institucionalizada encargada de proporcionar pasaportes, contratos, y pasajes de embarque falsos a precios abusivos de cincuenta mil, treinta mil, veinticinco mil, diez mil pesetas, etc .Esta mafia tenía buenos resortes, estaba bien organizada y cuando los descubrieron, pudieron escapar vía Lisboa”

(Testimonio de un retornado de Brasil, abril 1992). ${ }^{23}$

"El irme me costó veinticinco mil pesetas, repartidas entre : siete mil pesetas el billete de barco, dos mil pesetas el contrato de trabajo, otros gastos de varios viajes a Cádiz para arreglar los papeles, y algunas cosas que compré como escopetas, artesanías que, según tenía entendido, se cotizaban bien allí. Cuando llegué al puerto de Santos, me quedé el último para pasar por la aduana, y como la policía ya estaba cansada no miró el baúl donde llevaba las escopetas, si hubiera tenido que pagar impuesto de aduana no hubieran sido éstas rentables. Con lo que ahorré y con la venta de las escopetas, pude volver a España a los dos años, con algo más de cinco mil duros (25.000 pesetas), pues no quería que mi mujer me dijera cuatro cosas..."

(Testimonio de un retornado de Brasil,abril de 1992). ${ }^{24}$

\subsection{El desgarro que produce el hecho migratorio}

- Presentamos tres descripciones : una sobre el desgarro de la despedida; y dos sobre el viaje al "nuevo" y "otro" mundo, un viaje, como de parto, iniciático en definitiva :

"La despedida, Ay!, muy mal, bastante mal. Ya te digo yo, cuando yo llego a mi casa para despedirme, por la calle de la Esparraguera, sentía los gritos de mi madre. Y llegamos allí, mi padre justo había salido de la pieza, estaba poniéndose (abrochándose) el botón del chaleco, estaba allí llorando, era todo un drama. Yo no me quiero acordar, ¿por qué, para qué...?”

(Testimonio de una inmigrante, julio de 1993, San Miguel de Tucumán) ${ }^{25}$

“ Perdida, yo estaba perdida... Y veía la comida y me daba asco...y había bailes, y mi marido me decía "baila, hija...". Yyo le decía "a mí me dejas tranquila que yo me acueste. Luego tenía al Miguel, con un año de edad, casi muerto, con unas fiebres que volaba”

(Testimonio de una inmigrante, tomado en julio de 1993 en San Miguel de Tucumán.) ${ }^{26}$

-En el siguiente extracto testimonial no sólo aparece el desgarro de la ida sino también las causas, financiación y descripción del viaje:

"Y para mí aquello fue tétrico, cuando vi que el anterior día a nuestro embarque estaba atracado en el puerto de Cádiz aquel ataúd blanco que era el "Cabo de Hornos", se me acabaron hasta las ganas de vivir, y yo que iba al frente de un grupo por tener 30 años, y yo era el más inútil de los cuatro (mi padre tenía 60 años, mi madre 58, y mi hermana 26), porque yo no sabía nada de nada. Entonces, claro, yo me metí en aquel barco, cuyos pasajes costaron

\footnotetext{
22 Ibídem.

${ }^{23}$ PÉREZ MURILlO, María Dolores : Oralidad e Historias de Vida..., o.c., pág.: 125

24 Ibídem.

${ }^{25}$ Ibídem. Pág. 164

${ }^{26}$ Ibídem. Pág. 163
} 
72.000 pesetas, porque fuimos obligados a viajar en camarotes de lujo, de cuatro plazas, como turistas elegantes, cuando yo tenía que haber ido en la panza del barco como iban todos aquellos desgraciados (...) alli estaba subyacente todo un mundo, habia mil, dos mil personas que iban en busca de un horizonte perdido... Y ya a través del Océano empezó la tragedia: con escala en Dakar, donde yo vi hacinada la miseria humana del negro, tirados en la calle, arrojados frente a los grandes negocios franceses (...) Alli fue donde yo me di cuenta del destino que a mi me esperaba. Que cuando llegué a América no fue así como yo lo ví en Dakar, pero fue algo parecido"

(Testimonio, tomado en julio de 1993, a un inmigrante residente en Rosario (Argentina) y emigrado en 1952) ${ }^{27}$

\section{4.- CARACTERÍSTICAS DE LA INMIGRACIÓN DE INDÍGENAS SARAGUROS ECUATORIANOS EN EL MEDITERRÁNEO ANDALUZ (VERA-ALMERÍA) A TRAVÉS DE EXTRACTOS TESTIMONIALES}

A continuación, a través de fragmentos testimoniales, tomados en Vera (AlmeríaEspaña) y procedentes del trabajo de campo que allí realizamos (en el verano de 2002) Eva $\mathrm{M}^{\mathrm{a}}$ Díaz Buzón y yo, podemos perfilar las características cotidianas, es decir, la intrahistoria de la inmigración indígena en España. Dejemos, pues, que nos hablen sus propios protagonistas y nos expliquen las características del éxodo a través de las causas, de las fuentes de financiamiento del viaje y del desgarro que toda diáspora genera:

\subsection{Causas de la emigración}

Todos los testimonios vienen a reseñar como causa prioritaria la crisis económica y la galopante inflación por la que pasó y aún atraviesa el Ecuador de fines del siglo XX a causa de la imposición de la economía neoliberal y la consecuente dolarización (en septiembre de 2000). Al respecto, traemos a colación el siguiente testimonio de una mujer, inmigrante saragura ${ }^{28}$ :

"El asunto económico en Ecuador estaba demasiado caído, que (como) decimos nosotros. Pues ya nosotros trabajando los dos no nos alcanzaba el dinero para mantener a los niños. Salíamos a trabajar todos los días por la mañana temprano y llegábamos a la tarde, muy de tarde. Manuel más de tarde, yo más pronto pero ni aún, mas seguíamos yendo a los pocos sembrados que teníamos a trabajar alli en la tarde. Pero igual ya no nos alcanzaba ni así...Ese dinero se invertía solamente en comer, educación, vestidos y así...Cobrábamos y quedábamos sin nada... Cada día en una semana era un precio distinto...y hasta que yo me acuerdo que el quintal de arroz (unos 40 kilos) que comprábamos nosotros estaba a 700.000 sucres (28 dólares), y mi sueldo era de unos 100 dólares. Pero que eso (el arroz) en familia (para 7 miembros de familia) no duraba ni un mes ese arroz. Solamente en la compra de de ese saco de arroz se iba más de la cuarta parte del sueldo. Que el sueldo nos alcanzaba para comprar un saco de papas, otro saco de arroz y así poco más. Estuvimos en las nubes, en las nubes

estuvimos."

\footnotetext{
${ }^{27}$ Ibídem. Pág.196

${ }^{28}$ Testimonio tomado en Vera (Almería-España) en julio de 2002 a una indígena saragura, de unos 40 años de edad, profesora en su país de enseñanza primaria, madre de familia, de 5 hijos (3 mujeres y 2 varones, comprendidos entre los 10 y 20 años) y abuela de un nieto, recién nacido. Primero emigró su marido, de 42 años, en 1998, y al año siguiente emigró ella, dejando a sus hijos a cargo de la abuela materna en Saraguro; y tras varios intentos progresivos fue luchando para traerse a sus hijos a España, y consiguió reagrupar a toda la familia en menos de 3 años. Actualmente el marido está empleado en un horno de pan, y ella y sus hijas mayores trabajan en el servicio doméstico y en la hostelería (servicios de limpieza). Se trata, por tanto, de un núcleo familiar totalmente integrado al lugar receptor; pero no asimilados, ya que ellos mantienen muy vivas las señas de identidad indígena, sobre todo el cabeza de familia, el cual fue profesor de la escuela bilingüe (quechua-castellano) en Saraguro. El matrimonio sobrevivía en Ecuador con las escasas nóminas de docentes (100 dólares cada una) y con el trabajo en el huerto de producción familiar y autoconsumo
} 
A los desequilibrios económicos de la inflación galopante hay que añadir la total desprotección del Estado hacia los ciudadanos, la ausencia de Seguridad Social y la inexistencia de sanidad pública. Al respecto un médico ecuatoriano, profesor de la Universidad del Azuay (Cuenca-Ecuador) nos testimonia lo siguiente:

"En cuanto a la Sanidad, el estado dedica sólo el 3\% del P.I.B. La sanidad está totalmente privatizada. Sólo el cabeza, o sea el que cotiza dentro de la unidad familiar, tiene derecho a una mínima asistencia sanitaria, de atención primaria y cirugía básica; pero está obligado a pagar los remedios, es decir: las medicinas e, incluso, los hilos para coser una herida. Existen magníficas clínicas privadas con servicios y precios como los del primer mundo, en donde algún migrante, indígena o mestizo, recién venido de los EE.UU., se somete a una operación de cirugía estética, como por ejemplo: "para conseguir un perfil griego"...Mira, te pongo un ejemplo claro, rápido y práctico de que es lo que ocurre. No es tan aislado lo que voy a contar. Llega al hospital una lavandera, una persona que puede estar ganado 80 dólares al mes, llega con el hijo con un diagnóstico de apendicitis. Se le dice a la persona: "usted tiene que pagar 80 dólares para que su hijo se opere". Dice la señora: "si es por eso, que mi hijo se muera porque yo no tengo...¿Qué tienes qué hacer ahí como médico?: hacer una "vaca”, es decir, una contribución entre los médicos que están de guardia para pagar una sotura y para un anestésico" 25

Siguiendo con la pésima infraestructura sanitaria y la total desprotección del Estado respecto a los ciudadanos, ya que el Estado dejó de existir, y hoy sólo tenemos la ley de la empresa que todo lo ha privatizado de manera alarmante, nos hallamos con un testimonio que nos denuncia esa situación como causa de diáspora migratoria: La informante es una mujer, indígena saragura, de 33 años, casada desde hace una década y madre de 4 hijos varones, comprendidos entre los 2 y 15 años de edad. Esta mujer emigró junto con su esposo a España con el móvil primordial de poder pagar la operación de uno de sus hijos, de 11 años de edad, que había nacido con un serio problema de hipertensión portal, enfermedad, que requiere constantes cuidados y gastos médicos, que el matrimonio (el marido empleado en la construcción y la esposa dedicada al cultivo y venta semanal de hortalizas, procedentes del minifundio familiar) no podía asumir debido al carácter privado de la medicina y la ausencia de seguridad social. La desesperada situación económica de la familia, la grave enfermedad del pequeño de 11 años y los altísimos costes del complejo proceso operatorio atrajeron la atención de la alcaldía, la iglesia católica y personas anónimas de Saraguro que ofrecieron donativos a la familia para aliviarla en tan difícil coyuntura; aún después de recibir tan estimadas ayudas, la familia se vio obligada a adquirir un préstamo de 9.000 dólares para financiar el resto de los gastos médicos, viéndose el matrimonio obligado a emigrar a España, cayendo en las redes de los prestamistas o chulqueros a los que hubieron de hipotecar la casa. Primero emigró el marido a Vera (Almería-España) siguiendo redes de paisanaje establecidas en dicho lugar, y tras 4 meses de absoluto silencio del cónyuge, la esposa, acosada por los prestamistas, se vio obligada a emigrar también para poder hacer frente a la deuda; y los hijos, 3 de ellos habidos con su marido, se quedaron en Saraguro bajo la custodia de la abuela paterna; pero el hijo mayor, de 15 años, fruto de una relación previa al matrimonio, "fue acogido" por la familia materna, que vivía lejos, en el Oriente (o zona amazónica), no sin antes rogar y suplicar insistentemente la informante y prometer el pago de una contribución económica a su familia por hacerse cargo del hijo adolescente. Traemos a colación un fragmento de una causa más de la emigración debido al abandono de las instituciones estatales, presas del capitalismo salvaje imperante:

"En Saraguro no trabajaba en nada, me dedicaba a la agricultura. Cultivaba hortalizas, que iba a vender a mediados de semana y los fines de semana, y con eso...a medias he mantenido a mis hijos. Mi marido igual, el trabajaba en la construcción, pero era muy difícil para él conseguir trabajo que no había todas las semanas, que tenía que trabajar tres días, un

\footnotetext{
${ }^{25}$ Testimonio tomado en Cádiz en febrero de 2003 a un médico anestesiólogo y profesor de la Facultad de Medicina de la Universidad del Azuay, residente en Cuenca (Ecuador)
} 
día a la semana...Era muy difícil vivir allá (en Saraguro) y como mi hijo ha vivido los ocho años con tratamiento que teníamos que comprar por cajas. Mi hijo tomaba cada 12 horas la medicina...Mi hijo tenía varices en el esófago y la operación, la operación, costaba 9.000 dólares en el Ecuador, y para pagar la misma hemos tenido que emigrar mi marido y yo...Bueno me han ayudado... tenemos en total (la deuda) de 9.000 dólares a pesar de que nos han ayudado el pueblo, el párroco, la clínica de Santa Ana, nos han ayudado mucho...Una persona particular que se dedica a hacer préstamos nos hizo un préstamo que teníamos que pagar al $10 \%$ y tuvimos que hipotecar mi casa". ${ }^{29}$

Para concluir este primer apartado de causas de la emigración, podríamos mencionar lo que se denomina el efecto "dominó" como una causa más y secundaria que se suma a todo proceso de diáspora, así no lo testimonian algunos informantes:

"Todas las personas decían "vamos a viajar a España”

“Toda la gente, ya unos y otros... entre compañeros nos decíamos, bueno mira, a ver si nos vamos a España, y bueno esa fue la decisión y ya bueno, sintiendo la necesidad era...el vocabulario común, "que nos vamos a España, nos vamos a España”.

\subsection{Infraestructura material de la emigración: fuentes de financiación y costes del} viaje

En primer lugar hemos de aclarar que la emigración es un proceso excluyente y que, contrario a lo que se pueda pensar, en ella participan personas con recursos, por lo general de clase media o media baja. La élite indígena, aunque minoritaria, no tiene interés por emigrar o abandonar la situación, casi de "primer mundo" en su propio país; y los que pertenecen a las clases más bajas no cuentan con recursos económicos suficientes para financiar los elevados costes del proceso migratorio. Los que emigran, pues, son los que tienen acceso al capital, ya sea a través del patrimonio activo o pasivo, que les permite la obtención de un crédito. En la mayoría de los casos los usureros locales, denominados chulqueros, prestan dinero tomando como garantía la hipoteca de tierras o casas. Esta operación de hipoteca de la propiedad familiar es ciertamente arriesgada, si tenemos en cuenta que, a menudo, la propiedad de un terreno es el único medio de subsistencia para una familia, y de resultar fallido el intento de emigración el impago de la hipoteca implica la pérdida de la propiedad. La emigración para los saraguros se entiende como un compromiso, "empresa" o inversión familiar en el que uno de los miembros pone el riesgo de la hipoteca de sus propiedades y el otro miembro adquiere el compromiso de aportar recursos materiales a la familia tras su emigración. Testimonios de inmigrantes ${ }^{30}$ nos hablan al respecto

"Mi madre garantizó así, no más, con letras de cambio, y mi suegra hipotecó el terreno. Un terreno bien grande con casa, un terreno bien grande...Ella sabía sacar mucho dinero siempre, y como ella ya ha devuelto todo el dinero, la conocen y por eso le han prestado el dinero, como se dice "así no más"”.

"(Si no pagamos) pues, seguramente van a hipotecar ese terreno y el de mi madre también. Yo creo que han de buscar algo para la liquidación y para hipotecar. Últimamente he hablado con ella y me ha dicho que cada vez más van subiendo los intereses...”

Tras entrevistar a numerosas personas que han vivido la experiencia inmigratoria, estamos en disposición de ofrecer unos datos generales del coste al que asciende el viaje: el pasaporte cuesta de 50 a 100 dólares que hay que pagar en el Banco del Pacífico; el transporte terrestre Saraguro-Quito en autobús por la carretera Panamericana con una duración de 18 horas

\footnotetext{
${ }^{29}$ DÍAZ BUZÓN, Eva María, op., cit.

${ }^{30}$ Ibídem
} 
y unos 800 kilómetros se estipula entre 50 y 70 dólares; billete de avión Quito-Madrid-Quito ${ }^{31}$ entre 1.500 y 2.000 dólares; bolsa de viaje entre 1.500 y 2.000 dólares $^{32}$; estancia de una noche en Madrid entre 40 y 70 dólares; gastos varios, 30 ó 50 dólares. El total ascendía en el año 2002 de más de 3.000 a 4.500 dólares. A estos precios hay que añadir el pago de los intereses acumulados hasta saldar el préstamo. Los intereses medios, citados por nuestros informantes, rondan entre el 6 y/ó $10 \%$ mensual que multiplicado por los 12 meses del año viene a suponer entre un $72 \%$ y $120 \%$ anual. La acumulación de estos intereses al capital inicial supone que el inmigrante tendrá que devolver más de 5.500 dólares en el mejor de los casos y más de s 9.500 en el peor de ellos.

Sin duda, emigrar a España es más barato y menos peligroso que a los EE.UU. de Norteamérica, ya que las dificultades de llegar hasta "El Norte" son mayores pues hay que utilizar varios tipos de transporte : aéreo, naval, por carretera, lo que supone una cuantía de 15.000 a 25.000 dólares, amén de los inmensos riesgos físicos y humanos del trayecto, sobre todo, si éste se hace por transporte terrestre a través de Centro-América y México.

Acerca de los gastos del viaje a España, contamos con varios extractos testimoniales, fruto de nuestro trabajo de campo en Historia Oral, llevado a cabo en Vera (Almería) en el verano de 2002:

"Yo saqué el pasaporte, eso...en ese tiempo no había muchos, pero sí que había que hacer mucha cola. Es muy difícil (sacarlo) allí cobran mucho. (Me costó) un millón quinientos sucres, como 100 dólares, menos de 100 dólares."

"El pasaje me costó 2.000 dólares y la bolsa de viaje 1.500. Eso es lo que se paga en Loja. La agencia Bahía Sur me tramitó el pasaje. El pasaporte lo hacemos nosotros por nuestra propia cuenta, pero lo que se paga del pasaporte no es mucho...La bolsa de viaje ${ }^{28}$ se devuelve. Hay que pagar igual de la bolsa de viaje 40 dólares por el uso del dinero."

"La deuda de mi viaje me costó pagarla unos cinco meses, pues los intereses iban aumentando cada vez más. Si hubiese sido sólo el capital, hubiese sido más fácil de pagar.”

"Porque estaba haciendo cuentas y mejor me pongo a llorar. Yo digo cada vez parece que ya lo que mandamos no sé si rebaja un poco pero solamente los intereses. Igual el capital está igual. Y el total... estaba haciendo cuentas y ya estaba como que ya debíamos como 4.750 dólares, y si mandamos 550 igual nos quedan 4.200. Ahora que no estamos trabajando (ni mi marido ni yo), yo sé que tal vez no vamos a poder pagar dinero porque tenemos que pagar el piso

\subsection{El desgarro que produce todo hecho emigratorio}

Queremos dejar constancia que nadie emigra "por gusto o frivolidad" ni "por afán de aventura". De ese desgarro presentamos dos extractos testimoniales: el primero de un varón y el segundo de una mujer, ambos ecuatorianos, indígenas saraguros, residentes en Vera (Almería) ${ }^{33}$ :

"Era una experiencia muy amarga, realmente tener que dejar a esposa e hijos, yo que no estaba acostumbrado a vivir mucho tiempo fuera de la familia...Me sentía muy, muy extraño,

\footnotetext{
${ }^{31}$ El boleto ha de ser de ida y vuelta, ya que estos inmigrantes penetraban en España haciéndose pasar por turistas, con una estancia máxima autorizada de 3 meses, por lo tanto y para probar la intención de regreso se requiere billete de ida y vuelta. En mayo de 2003 y con la entrada en vigor de la nueva de extranjería, se les obliga a las empresas de transporte aéreo a llevar un control del retorno de los inmigrantes so pena de ser sancionadas con una multa de 60.000 euros (este último dato apareció publicado en el periódico "El País" el 24 de mayo de 2003)

${ }^{32} \mathrm{La}$ "bolsa de viaje" es la cantidad de dinero que hay que declarar al llegar a la frontera española para demostrar que se visita este país como turista. Este dinero se le presta al emigrante por unos días, debiendo pagar 40 dólares de interés por cada día que retenga dicha cantidad. La transferencia bancaria de la "bolsa de viaje" está en torno a los 20 ó 30 dólares. Las agencias que expenden el viaje proporcionan también la referida "bolsa"

33 Testimonios Orales tomados en por Eva Ma Díaz Buzón y María Dolores Pérez Murillo en julio de 2002 en Vera (Almería). Estos mismos están reproducidos en la Tesis Doctoral de Eva Ma Díaz., defendida en Cádiz el 12 de septiembre de 2003 .
} 
que jamás en mi vida yo había pensado realizar esta sorpresa de movimiento, de emigrar a un lugar tan, tan lejano...Ya sintiendo con esa necesidad, pensando de que, bueno lo estoy haciendo por mi familia, no estoy yéndome porque yo quiera abandonarles por..., como yo digo desánimo de cariño, sino más bien porque yo les quiero a ellos y que mi familia surja (resurja), entonces con esa intención o, mejor dicho, con ese pensamiento me vine. (Mi partida) fue como un parto."

"En ese vuelo, digo por suerte, nos tocó venir a nosotros a diecinueve indígenas de Saraguro, pero que, por coincidencia, en el aeropuerto nos encontramos. Como yo estaba viniendo sola, porque acostumbrábamos a salir (de Saraguro) en ese tiempo, pues calladitos de todo, sin que nadie lo sepa...Yo nunca había tenido oportunidad de viajar, yo ni soñando siquiera (ríe). Bueno, ya era de viajar en avión, y digo ¡Dios mío!, ¿y ahora?, subirnos en el avión, ¡nos vamos a morir!... (Ríe). Digo, si se cae el avión no vamos a quedar ni un pedazo aquí. Tal vez mucha gente esté acostumbrada a viajar pero yo no. El avión estaba en el aire. Pufff..., yo nerviosa, que no me daba ganas de moverme...Ya comenzó el avión de Quito y dije “iAy, Dios mío!, Señor yo no quiero...”. Entonces la mujer que había a mi lado me hablaba en el avión y me decía: “¿Para qué estas llorando, para qué lloras?, si tus hijos son grandes y ellos no te necesitan para que les des el pecho...”; pero ella iba un poco mareada. Ella me decía: "tómate, Carmen, un poco de cerveza". Digo: "no, yo no quiero tomar nada para nada lo quiero". Entonces, ella cuando vinimos al hotel se le pasó todo eso que tenía en la cabeza y luego ella se ponía a temblar en el hotel como una loca. Entonces yo le digo, "eso te pasa porque tú viniste bebiendo en el avión, por eso no sentías por tus hijas nada; en cambio, yo estuve llorando pero ya lo pasé, ya me salieron todas las cosas en las lágrimas. Pero digo, "a ti ahora, mira cómo estás, como una loca”. Porque se puso demasiado mal en el hotel, que me daba miedo porque quería yo llevarla a un médico porque estaba temblando y se ponía a llorar en la noche. Me daba pena y miedo, a mí me pasó todo el sentimiento que yo tenía, y ya luego, ya amanecido, bueno, no dormimos, porque al igual yo estaba cuidándola a ella, me daba miedo parece que iba a morir..."

\section{CONCLUSIONES}

1. Con el presente artículo hemos pretendido mostrar las características similares entre la emigración de andaluces del Mediterráneo hacia América Latina y los latinoamericanos que actualmente viven y trabajan "con" o "sin" papeles en la coyunturalmente próspera región mediterránea. Y digo coyunturalmente porque, como historiadores no podemos olvidar, que la Andalucía del Litoral Oriental fue un lugar otrora deprimido que expulsó a sus hijos a la diáspora; pero hoy, gracias a los planes de colonización rural del anterior régimen (franquismo) y gracias al turismo, "por arte de magia", dicho litoral se ha convertido en una efímera "tierra de promisión", tierra sometida a una exhaustiva y especulativa explotación del suelo y de sus escasos recursos hídricos. En definitiva: la construcción irracional y la agricultura "bajo plástico", fuentes de riqueza y de trabajo para inmigrantes, comienzan a mostrarnos su cara oculta, manifiesta en el deterioro de las relaciones humanas (xenofobia y altos índices de criminalidad), y, por supuesto, el caos medioambiental que estamos comenzado a padecer. Ante todo ello los poderes públicos "hacen oídos sordos".

2. También queremos demostrar que el prototipo de emigración de andaluces del Mediterráneo a América y de latinoamericanos en esta zona es similar: pequeños agricultores o propietarios de algún inmueble (casa primordialmente) que, ante la socialización de las crisis de sus respectivos países, se ven obligados a vender o a hipotecar sus escasos bienes a los usureros y pactar con las mafias locales (ganchos en Andalucía, coyotes en América) para emprender el largo viaje extracontinental sin 
papeles o "con papeles falsos" ${ }^{34}$. Evidentemente este tipo de emigración posee un carácter excluyente, hay que los que emigrar, aunque son pobres, no son los míseros, es decir: los excluidos de todo.

3. Toda emigración produce un profundo desgarro: en todos los casos, que hemos analizado, las personas no emigran por "gusto" ni "por frivolidad" ni "para delinquir". Emigrar es un mal menor necesario, es la única salida del que todavía "tiene pellejo que salvar" ante la irresponsabilidad del Estado, ante la socialización de la deuda contraída por políticos y caciques corruptos.

4. Para finalizar, deseo proponer desde estas líneas la imperiosa necesidad por parte del Estado en una seria y responsable inversión en políticas públicas de acogida e integración de inmigrantes, como únicas vías para evitar las bolsas de miseria y delincuencia. Condonar la deuda externa a los países, generadores de diáspora, y que dicha condonación sea para invertir en bienes sociales y capital humano a fin de evitar el desangramiento que supone la emigración

\footnotetext{
${ }^{34}$ Las cartas de llamada o contrato de trabajo que exhibían los andaluces del Mediterráneo a las autoridades portuarias de Santos, Buenos Aires, Montevideo no eran reales. A la mayoría de ellos nadie los reclamaba allá. Consultar el libro que se cita completo en la nota, a pie de página, número 2 del presente artículo.
} 